\title{
A Hierarchical Methodology for Performance Evaluation Based on Data Envelopment Analysis: The Case of Companies' Competitiveness in an Economy
}

\author{
Mohamed Dia ${ }^{1}$, Fouad Ben Abdelaziz ${ }^{2}$ \\ ${ }^{1}$ School of Commerce and Administration, Laurentian University, Sudbury, Canada \\ ${ }^{2}$ ESM Graduate Program, American University of Sharjah, Sharjah, UAE \\ E-mail:mdia@laurentian.ca,fabdelaziz@aus.edu \\ Received July 22, 2011; revised August 17, 2011; accepted September 7, 2011
}

\begin{abstract}
In this research, we present a hierarchical Data Envelopment Analysis (DEA) methodology for competitiveness analysis. This methodology takes into account the heterogeneity of the decision making units (DMUs) as well as the diversity of the comparison criteria. We propose to homogenize the DMUs by grouping them hierarchically, which permits a better identification and definition of the criteria in each specific grouping. The methodology proceeds first by the determination of the performances or relative efficiencies, which are in turn aggregated into competitiveness indices in each grouping by the superiority index of [1]; then, the overall competitiveness indices are determined additively along the hierarchical levels. We illustrate the methodology by a competitiveness analysis of several companies belonging to different sectors of activity in an economy, where are suggested ways of improvement for the non-competitive companies within their sectors and within the economy.
\end{abstract}

Keywords: Data Envelopment Analysis, Heterogeneity, Hierarchies, Competitiveness Analysis

\section{Introduction}

As there is no perfect system to effectively evaluate the competitiveness of a company, managers typically use a range of measures of a financial and non-financial nature, both internal and external. The importance and popularity of these measures vary considerably over time and from one company to another. The typical approach consists, in most cases, in identifying the same measures of competitiveness for each company, measuring them in the same manner, and calculating an index of competitiveness for each firm using a given model. This approach is acceptable if these companies are fairly homogeneous but it becomes inappropriate if the homogeneity of the companies is not evident. This is the case if the companies belong to different sectors or to different environments (countries, regions, economic areas, etc.). Indeed, in today's world, it would be illogical to evaluate biotech, electronic, aeronautical, agricultural, or textile companies using the same indicators of competitiveness and in the same way.

Data Envelopment Analysis [2] is a technique for meas- uring performance, which is defined in this research as a relative efficiency. Its application in competitiveness analysis was suggested for the first time by [3]. Subsequently, [4] proposed using the model of [5] to measure the competitiveness of nations, and [6] used the Moving Frontier Analysis to perform a competitiveness analysis of high-tech factories. All these studies have demonstrated that DEA was appropriate for the study of competitiveness analysis problems because it provides, through the principle of data envelopment, a reference for current and potential comparison to organizations for effective formulations of competitiveness strategies.

However, evaluating the competitiveness of companies requires the selection of the most appropriate competitiveness indicators and the use of appropriate models. These determinants are usually multiple and very diverse and, as the company is not an isolated actor in its environment, its competitiveness is influenced by the industry and the nation. Indeed, [7] state that sector membership of a company is a source of influence on the potential competitiveness of this company. For its part, $[8,9]$ argues that the environment in which firms operate af- 
fects significantly their competitiveness and that of their industries. Meanwhile, [10] suggests that it is useful to consider competitiveness at three different levels of aggregation: the enterprise, the industry, and the country as a whole. For each level of aggregation corresponds various indicators of competitiveness that differs depending on whether it is economic growth or the current and future well-being of a company, a sector or a country that is under consideration. It is to be noted also that some notions of competitiveness only apply to a given level of aggregation and not to others.

Our study is considered within this context and proposes an approach to measure the competitiveness of heterogeneous companies in an economy where, it is important to take into consideration both their basic and specific characteristics of companies under consideration. We propose, therefore, following the approaches advocated by [7-10] to use a tree structure with three levels (company, industry and economy) to better identify the competitiveness indicators of companies in an economy. The competitiveness of a company in an economy is then a combination of the competitiveness of its sector within this economy and the competitiveness of the specific company in this sector. Two key points underlie this approach. First, a company's industry membership has a decisive influence on its competitiveness, not only within its own economy, but also by comparison with the same sector in different economies [7,8,10,11]. Second, some companies' competitiveness indicators are valid only for certain sectors and the same for those of sectors in certain economies [8-10]. In addition, the common indicators may not necessarily have the same importance for one company in comparison to another, especially if these companies come from different sectors within different economies. Indeed, in such situations, the technologies used on both sides are different and characterized by the industry or the economy. Our methodology is the first one, to our knowledge, to propose an analytical model to measure the competiveness of heterogeneous companies, and also the first one using a hierarchical structure in DEA in this context.

Our proposed model, which is based on the DEA technique [2], meets the need expressed by [12] for a formal model-based approach to competitiveness analysis that managers or policy makers can use for strategic decision making. However, given that DEA is designed to evaluate homogeneous units, we propose to adapt the technique into a tree representation form with two grouping levels (economy and sectors) so as to homogenize the data in each level. Our approach is also the first one to propose an explicit way to homogenize the DMUs in DEA by adopting a hierarchical structure when there are heterogeneity problems. The conceptual hierarchical struc- ture of our problem is presented in Figure 1 where the economy consists of $n$ sectors evaluated on $c$ performance criteria and where for each sector $s$, there are $n_{s}$ companies evaluated on $c_{s}$ performance criteria. To our knowledge, no study has so far treated a similar conceptual and methodological structure, although some studies using DEA in hierarchically structured problems have been conducted [13-16]. For example, [14,16] evaluated the relative efficiency of several power stations, each consisting of several units and defined same inputs-outputs for the units and the power stations with few specifics for the latter. The inputs-outputs shared between power stations and power units were aggregated additively to the top level of the hierarchy to assess the relative efficiency of the power stations. In turn, [15] used an approach similar to that of [14] and [16] where the units and sub-units were, respectively, the universities and their faculties or departments. For their part, [13] provided a classification of the DEA models that had assessed DMUs whose internal structure was know and could be represented as hierarchical networks. All these authors [14-16] also confirm that taking into account the hierarchical structure of the problem allows for a better assessment of the units under study.

Now consider that the criteria of competitiveness of each level consist in criteria to maximize and criteria to minimize (by analogy, respectively, outputs and inputs of DEA), and that we have the data at all levels (companies and sectors). The notations used in this research are:

$n$ number of DMUs (companies or sectors)

$t$ number of outputs (criteria to maximize)

$m$ number of inputs (criteria to minimize)

$x_{i j} \quad$ value of input $j$ for $D M U_{i}$

$y_{i k} \quad$ value of output $k$ for $D M U_{i}$

$P_{i j}^{E} \quad$ performance of sector $i$ from the point of view of sector $j$ in economy $E$

$P_{i j}^{S} \quad$ performance of company $i$ from the point of view of company $j$ in sector $S$

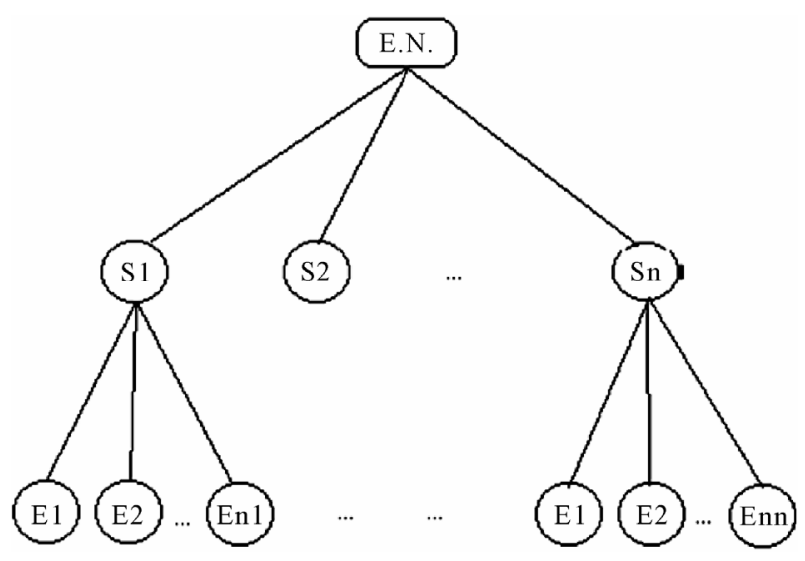

Figure 1. Hierarchical structure of the problem. 
$\mu_{r} \quad$ virtual multiplier (or relative importance) of output $r$

$v_{s} \quad$ virtual multiplier (or relative importance) of input $s$

$\varepsilon \quad$ small positive real value

The remainder of the paper is structured as follows. In Section 2, we develop the main models for calculating the performance of sectors in the economy and those of companies in their respective sectors. Then, in Section 3, we proceed to the aggregated performance to calculate the various indices of competitiveness. Section 4 shows the application of our methodology and illustrates the ways of improvements for companies and sectors. Finally, Section 5 summarizes the paper and presents future research issues.

\section{Calculation of Performances}

The performance is defined here as the relative efficiency ratio of DEA [2] which is the weighted sum of the outputs over the weighted sum of the inputs, and takes its values within 0 and 1 . In a first stage, we evaluate the performance of sectors in the economy, and then in the second stage, we evaluate the performance of companies in their respective sectors. In both stages, we use crossefficiency evaluations $[17,18]$, which aim to reflect the strategies of competitors on the performance of each unit (company or sector) and discriminate among these sectors and companies.

All models presented in this section are related to that of [2] and can therefore be solved by the transformation of [19]. There are no restrictions on using other types of DEA models such as the models of [20] and those in [21] for example.

\subsection{Performance of Sectors in the Economy}

The performances of the sectors are determined by conducting cross-efficiency evaluations among sectors. These cross-efficiency evaluations consist in first determining the maximum performance of each sector according to its own point of view (1) subject to the requirement that the performances of all other sectors do not exceed one (2) for the same values of the virtual multipliers (3). The same virtual multipliers are used to calculate the maximum performance of all the other sectors according to the point of view of the considered sector. However, in some situations, there is no uniqueness of the virtual vector of multipliers that gives a maximum performance in the model (1-3). In this case, the model (4-7) also known as a benevolent formulation (see $[17,18]$ ) will be used to choose among these vectors of multipliers the one that, according to the point of view of this sector, gives the maximum performance for each other sector. However, there is no restriction to use other cross-efficiency models as those discussed in [18,22].

Let $x_{i s}$ and $y_{i r}$ be the values of the input $s$ and the output $\mathrm{r}$ for the sector $i\left(S_{i}\right)$. The evaluation of sector $i$ by itself (self-evaluation) or, in other words, the performance level of sector $i$ in its strategy is obtained as follows:

$$
\begin{aligned}
& \operatorname{Max}_{i i}^{E}=\frac{\sum_{r=1}^{t} \mu_{r} y_{i r}}{\sum_{s=1}^{m} v_{s} x_{i s}} \\
& \frac{\sum_{r=1}^{t} \mu_{r} y_{j r}}{\sum_{s=1}^{m} v_{s} x_{j s}} \leq 1, j=1, \cdots, n \\
& \mu_{r}, v_{s} \geq \varepsilon
\end{aligned}
$$

where $\mu_{r}, v_{s}$ are the coefficients of importance (or virtual multipliers) of outputs $r$ and inputs $s$ of $S_{i}$ and are the decision variables.

After their self-assessments, each sector $j$ will evaluate each of the other sectors $i$ or, in other words, it will determine the level of performance that it gives to sector $i$ in its strategy. The evaluation of sector $i$ by sector $j$ is performed as follows:

$$
\begin{aligned}
& \operatorname{Max} P_{i j}^{E}=\frac{\sum_{r=1}^{t} \mu_{r i j} y_{i r}}{\sum_{s=1}^{m} v_{s i j} x_{i s}} \\
& \frac{\sum_{r=1}^{t} \mu_{r i j} y_{j r}}{\sum_{s=1}^{m} v_{s i j} x_{j s}} \leq 1, j=1, \cdots, n \\
& \frac{\sum_{r=1}^{t} \mu_{r i j} y_{j r}}{\sum_{s=1}^{m} v_{s i j} x_{j s}}=P_{j j}^{E} \\
& \mu_{r}, v_{s} \geq \varepsilon
\end{aligned}
$$

After this first stage, i.e. the mutual evaluations of sectors, we get the performance matrix of sectors in the economy that we denote by $P^{E}=\left(P_{i j}^{E}\right)_{i, j=1, \cdots, n}$. Subsequently, we turn to the second stage to evaluate, in each sector, the performance of the companies that belong to this sector.

\subsection{Performance of Companies in Their Sectors}

In the same way that we calculated the performance of sectors in the economy, the mutual evaluations of companies in their respective sectors are determined according to models (8-10) and (11-14). The characteristics of the two models are equivalent to those of the previous models presented in Subsection 2.1 (above) and interpreted the same way.

Let $x_{i s}^{S}$ and $y_{i r}^{S}$ be the values of the input $s$ and output $r$ for company $i\left(E_{i}\right)$ of sector $S$. The self-evaluation of company $i$ of sector $S$, or in other words, its perform- 
ance in its strategy, is as follows:

$$
\begin{aligned}
& \operatorname{Max} P_{i i}^{S}=\frac{\sum_{r=1}^{t} \mu_{r} y_{i r}^{S}}{\sum_{s=1}^{m} v_{s} x_{i s}^{S}} \\
& \frac{\sum_{r=1}^{t} \mu_{r} y_{j r}^{S}}{\sum_{s=1}^{m} v_{s} x_{j s}^{S}} \leq 1, j=1, \cdots, n \\
& \mu_{r}, v_{s} \geq \varepsilon
\end{aligned}
$$

Similarly, the evaluation of company $i$ by company $j$ in the same sector $S$ (or in other words, its performance in the strategy of firm $j$ ) is as follows:

$$
\begin{aligned}
& \operatorname{Max} P_{i j}^{S}=\frac{\sum_{r=1}^{t} \mu_{r i j} y_{i r}^{S}}{\sum_{s=1}^{m} v_{s i j} x_{i s}^{S}} \\
& \frac{\sum_{r=1}^{t} \mu_{r i j} y_{j r}^{S}}{\sum_{s=1}^{m} v_{s i j} x_{j s}^{S}} \leq 1, j=1, \cdots, n \\
& \frac{\sum_{r=1}^{t} \mu_{r i j} y_{j r}^{S}}{\sum_{s=1}^{m} v_{s i j} x_{j s}^{S}}=P_{j j}^{S} \\
& \mu_{r}, v_{s} \geq \varepsilon
\end{aligned}
$$

At the end of this second stage, i.e. after the mutual evaluations of companies in all sectors, we get the performance matrices of the companies in their respective sectors that we denote by $P^{S}=\left(P_{i j}^{S}\right)_{i, j=1, \cdots, n}^{S}(S=1, \cdots, n)$ where $n^{S}$ is the number of companies in the sector $S$.

After calculating the mutual performances of sectors in the economy and companies in their respective sectors, we aggregate them in indices of competitiveness of sectors in the economy and indices of competitiveness of companies in their respective sectors. Then we combine/aggregate, for each company, its index of competitiveness in its sector with that of its sector in the economy to obtain its index of competitiveness in the economy. Finally, we suggest competitiveness analysis strategies for the companies and the sectors in order to improve their efficiency and their competitiveness.

\section{Measures of the Competitiveness Indices}

In order to reflect the effect of competition between the units (sectors and companies), their strategies are compared and their performances aggregated, for each unit, into a competitiveness index, which synthesizes the value of the unit in its group (that is, against other units). The aggregation method chosen is the superiority index of [1]. We define, first, a partial index of competitiveness by comparing all units one by one. Specifically, we es- tablish the comparison of two measures that each symbolizes a strategy, which is comparing two units $i$ and $j$ taking into account their own views of themselves and the perspective of each of them with regard to the others. This index is established from the matrices $P^{k}\left(=\left(P_{i j}^{k}\right)\right)$ calculated at level 1 (economy: $k=E$ ) and 2 (sector: $k=$ S).

The index of competitiveness between two units $i$ and $j$, which determines the amount by which unit $i$ is more (or less, according to the sign) competitive than unit $j$ is a partial measure computed as follows (see also [1]):

$$
I c_{i j}^{k}=\left[P_{i i}^{k}+P_{i j}^{k}\right]-\left[P_{j j}^{k}+P_{j i}^{k}\right]
$$

where $k=E$ or $S$.

We thus obtain a partial symmetric competitiveness matrix $I c^{k}\left(=\left(I c_{i i}^{k}\right)\right)$ at each level $1(k=E)$ and $2(k=S)$.

Second, from the partial index of competitiveness we deduce the overall index of competitiveness $(I C)$ which incorporates all the strategies of the units. The IC determines for each unit an aggregated measure symbolizing its value compared to all other units that takes into account all their strategies. It is calculated for a unit $i$ by the sum of its partial indices of competitiveness.

$$
I C_{i}^{k}=\sum_{j} I C_{i j}^{k}
$$

where $k=E$ or $S$.

Having thus measured and analyzed the $I c^{k}$ and $I C^{k}$ ( $k=E$ or $S$ ) of levels 1 and 2, we standardize them in order to determine the overall index of competitiveness of each company in the economy. The normalization procedure is as follows:

1) Sort the units from the best to the worst according to $I C^{k}(k=E$ or $S)$;

2) Determine the overall superiority intensity (OSI) of each unit compared to the unit preceding it in the list by subtracting the $I C$ of the current unit from that of the unit that precedes it (the last unit has an overall superiority intensity equal to zero: $O S I=0$ );

3) Sum, for each unit, the OSI with that of all the other units that precede it in the list;

4) Divide, for each unit, the OSI determined in the preceding step by that of the top unit to obtain its standardized $I C^{k}(k=E$ or $S)$.

The $I C^{k}$ (where $k=E$ or $S$ ), thus standardized, provides the same rankings to those $I C^{k}$ before the standardization, and their values range from 0 (worst) to 1 (best).

The index of competitiveness of a firm $i$ (belonging to sector $j$ ) in the economy is then determined as follows:

$$
I O C_{i}=\left(I C_{i}^{j}+I C_{j}^{E}\right) / 2
$$

where $I C_{i}^{j}$ and $I C_{j}^{E}$ are, respectively, the standardized 
indices of competitiveness of company $i$ in sector $j$ and of sector $j$ in the economy. This allows us to obtain the overall standardized index of competitiveness of each company in the economy, and ultimately a total ranking of the companies in the economy.

To summarize, our methodology proceeds in three stages as follows:

- Step 1: Calculation of the performances of companies in their respective industries and those of sectors in the economy,

- Step 2: Calculation of the indices of competitiveness of companies in their respective industries and those of sectors in the economy,

- Step 3: Calculation of the indices of competitiveness of companies in the economy.

\section{Illustration}

The illustration of our approach is performed on a simulated example of evaluating the competitiveness of 81 companies in an economy where the companies have been grouped into 6 sectors. This simulation is based on a confidential competitiveness analysis of Tunisian firms that we performed for the "Sécretariat d'État à la Recherche Scientifique et à la Technologie”. Given the current inability to publish this study, we opted for a simulation based on this real study to illustrate and validate our methodology. We generated data for the companies in their respective sectors and for the sectors in the economy. The sectors are evaluated on two criteria to minimize (inputs) and two criteria to maximize (outputs). Companies in sector 1 are evaluated on three inputs and two outputs. Companies in sector 2 are evaluated on three inputs and two outputs. Companies in sector 3 are evaluated on two inputs and four outputs. Companies in sector 4 are evaluated on four inputs and three outputs. Companies in sector 5 are evaluated on three inputs and four outputs. Companies in sector 6 are evaluated on one input and seven outputs. The tables in Appendix A show the data (columns whose titles begin with "in" correspond to inputs and those with "out" to outputs), efficiency ratios (column E.R.) and indices of competitiveness (column IC) of the sectors in the economy and of the companies in their respective sectors. The first table in Appendix B summarizes the rankings of sectors and companies in their groups while the second table of this appendix gives us the indices of competitiveness (column IOC) and the rankings of the companies in the economy (column Rank).

Table 1 of Appendix A which is the synthesized/summarized result of models (1-3) and (4-7), shows the data sectors, their efficiency ratios and their standard indices of competitiveness (calculated from equation 16). The resulting ranking gives sectors 4 and 3 the first and second places with indices of competitiveness of 1 and 0.9627 respectively, while the last two places are occupied by sectors 2 and 6 with indices of 0.2016 and 0 respectively. Similarly, Table 2 of Appendix A is a summarized result of models (8-10) and (11-14) for the companies in sector 1 . Thus, the ranking of the companies of sector 1 assigns companies 7 and 4, with indices of competitiveness of 1 and 0.8289 , to the first and second places respectively, while the last two places are occupied by companies 8 and 9 with indices of 0.0877 and 0 respectively. All rankings are reported in Table 1 of Appendix B.

At the aggregate level, Table 2 of Appendix B presents the standard indices of competitiveness (calculated from equation 17) and ranks companies in the economy. This ranking gives the first, second, third and fourth places to companies 17 in sector 4 (E17S4), 1 in sector 3 (E1S3), 16 in sector 4 (E16S4) and 15 in sector 4 (E15S4) with indices of competitiveness of 1, 0.9814, 0.9736 and 0.9639 respectively. The last four places are occupied by companies 5 in sector 2 (E5S2), 9 in sector 2 (E9S2), 13 and 16 in sector 6 (E13S6 and E16S6) with indices of 0.1836, $0.1008,0.0524$ and 0 respectively.

Strategic interpretations and recommendations related to the above analysis can be performed for sectors and companies. They are based on the results of dual programs (1-3) for the sectors, and (8-10) for companies in their respective sectors. The details of these results are only reported for the sectors in the economy (Appendix $\mathrm{C}$-Table 1) and for companies in sector 1 (Appendix $\mathrm{C}$ - Table 2) in order to reduce the size of the paper. With respect to the sectors, only sectors 3,4 and 5 are efficient. These results are reflected by the proportions of the contribution of each indicator in the efficiency ratio and therefore on the index of competitiveness. For sector 1 which is inefficient, for example, (its efficiency ratio is $0.9701<1$ ), the reference sectors are sectors 3 and 5 respectively with weights of 0.3881 and 0.5821 . The improvements needed for it to become efficient are to reduce its input 1 by 0.6866 , its input 2 by 0.7164 , and to increase its output 1 by 0.4179 (See Appendix C-Table 1). The same reasoning applies for all the other inefficient sectors. Just consider, for each sector, the improvements recommended on its indicators to make it more efficient and competitive. This suggests that actions in terms of economic policies are needed from the public authorities to improve the indicators used in the directions recommended in order to make the sector more competitive.

Similarly, for individual companies in their respective sectors, companies which are inefficient are identified and appropriate adjustments on some of their indicators 
are recommended based on their units of reference. For sector 1 , companies 4, 6, 7 and 10 are efficient, and all others are inefficient. In this case, company 1 of sector 1 has an efficiency ratio of $0.8466(<1)$ and its benchmark companies are companies 4,6 and 7 respectively with weights $0.5174,0.3885$ and 0.0573 . The improvements needed for it to become efficient in its sector are to reduce its input 1 by 1.5357, its input 2 by 0.1227 , its input 3 by 92.0246 and not to increase its two outputs ((See Appendix C-Table 2)). This suggests that management and planning actions are needed to improve the indicators used in the directions recommended in order to make the company more competitive.

Regarding now the improvements of the companies in the economy, we consider both the improvements of the companies in their sectors as well as those of the sectors in the economy. For company 1 of sector 1 to become efficient and more competitive in the economy, not only it must be adjusted in its sector, but its sector must also be adjusted in the economy. The optimal improvements for this company to become efficient are to reduce, in sector 1 , its input 1 by 1.5357 , its input 2 by 0.1227 , its input 3 by 92.0246 and not to increase its two outputs. In addition, its sector must reduce, in the economy, its input 1 by 0.6866 and its input 2 by 0.7164 while increasing its output 1 by 0.4179 . The same reasoning applies for all the other companies in the economy. Companies that are efficient in their sectors, and whose sectors are efficient in the economy do not require any specific improvements, but only some monitoring. Companies that fall into this category are companies $1,3,4,8,9,10,11,12$, 13 and 14 of sector 3 , companies 2, 5, 7, 9, 10, 11, 15, 16 and 17 of sector 4 , and companies 1, 2, 3, 4, 6 and 7 of sector 5 .

In order to explain or justify the level of competitiveness of a company $i$ belonging to a given sector $j\left(E_{i} S_{j}\right)$, one should adopt the same considerations as in the previous analysis by addressing the competitiveness of the sector $j$ in the economy and the competitiveness of company $i$ in its sector. For example, if $E_{i} S_{j}$ is weakly competitive at the global level, the reasons for this weakness in terms of competitiveness analysis can be explained or justified by the following: 1) the low level of competitiveness of company $i$ in its sector and, in this case, decision-makers must take the necessary steps to bring its competitiveness to the same level as the competitive companies in its sector $\left(S_{j}\right) ; 2$ ) the low level of competitiveness of the sector $j$ in the economy where, in this case, the company generally has no control or influence on the indicators of the competitiveness of the sector; however, it is to be noted that if this study was sponsored or supervised by public administration, authorities could then take the necessary actions (economic and trade policies) to improve the competitiveness of sector $j$ and therefore this will be reflected on the competitiveness of $E_{i} S_{j}$ in the economy; or 3) both scenarios may apply.

\section{Conclusions}

In this paper, we proposed a new methodology for evaluating hierarchical performance that we illustrated through a simulated case. Our methodology takes into account the heterogeneity of the companies to be compared. It suggests a tree structure form with two groupings (economy and sectors) in order to better identify and define the appropriate indicators of competitiveness. It calculates for each grouping level the performance ratios by using the DEA technique. In each grouping level, we also determined the indices of competitiveness of the compared units (companies and sectors). We have also proposed a combination of two grouping levels of performance to infer the performances and indices of competitiveness in the economy. Finally, the case studied and the results obtained demonstrate the applicability of the proposed methodology.

The approach developed here refers only to a case of evaluating companies in an economy using a single level of grouping through economic activity sectors. However, our approach, with the conceptual framework described here, could also be used in other areas. For example, it could be applied to a comparison of the competitiveness of globalized companies taking into account their affiliations to given countries, sub-regions, or economic spaces and providing new ways for grouping on several levels, where at each level several comparison indicators could be considered. Furthermore, as most economic and social information is by nature generally ambiguous, uncertain or unclear, it is also important to extend the competitiveness measure to the fuzzy context.

\section{References}

[1] O. Kettani, F. Ben Abdelaziz and M. Dia, "Méthodologie Multicritère Pour la Sélection de Projets d'Investissement en Tunisie,” In: M. Oral and O. Kettani, Eds., Globalisation and Competitiveness: Implications for Policy and Strategy Formulation, Bilkent University Press, Bilkent, 1997, pp. 381-396.

[2] A. Charnes, W. W. Cooper and E. Rhodes, "Measuring the Efficiency of Decision-Making Units,” European Journal of Operational Research, Vol. 2, No. 6, 1978, pp. 429-444. doi:10.1016/0377-2217(78)90138-8

[3] R. D. Banker, "Productivity Measurement and Management Control,” In: P. Kleindorfer, Ed., Management of Productivity and Technology in Manufacturing, Plenum Press, New York, 1985, pp. 239-257. doi:10.1007/978-1-4613-2507-9_10 
[4] M. Oral and H. Chabchoub, "On the Methodology of World Competitiveness Report," European Journal of Operational Research, Vol. 90, No. 3, 1996, pp. 514-535. doi:10.1016/0377-2217(94)00370-X

[5] M. Oral, O. Kettani and P. Lang, “A Methodology for Collective Evaluation and Selection of Industrial R\&D Projects,” Management Science, Vol. 37, No. 7, 1991, pp. 871-885. doi:10.1287/mnsc.37.7.871

[6] K. K. Sinha, "Moving Frontier Analysis: An Application of Data Envelopment Analysis for Competitive Analysis of a High-Technology Manufacturing Plant,” Annals of Operations Research, Vol. 66, No. 3, 1996, pp. 197-218. doi:10.1007/BF02187591

[7] M. Oral and O. Kettani, Eds., "Globalisation and Competitiveness: Implications for Policy and Strategy Formulation,” Bilkent University Press, Bilkent, 1997.

[8] M. E. Porter, "The Competitive Advantage of Nations," Harvard Business Review, Vol. 68, No. 2, 1990, pp. 73-93.

[9] M. E. Porter, Ed., "Competition in Global Industries," Harvard Business School Press, Boston, 1986.

[10] D. G. McFetridge, “La Compétitivité: Notions et Mesures,” Document Hors-Série Numéro 5, Industrie Canada, Ottawa, 1995, pp. 1-45.

[11] M. E. Porter, "Competitive Advantage: Creating and Sustaining Superior Performance,” Free Press, New York, 1985.

[12] M. Oral, “A Methodology for Competitiveness Analysis and Strategy Formulation in Glass Industry,” European Journal of Operational Research, Vol. 68, No. 1, 1993, pp. 9-22. doi:10.1016/0377-2217(93)90074-W

[13] L. Castelli, R. Pesenti and W. Ukovich, “A Classification of DEA Models When the Internal Structure of the Decision Making Units Is Considered," Annals of Operations Research, Vol. 173, No. 1, 2010, pp. 207-235. doi:10.1007/s10479-008-0414-2

[14] W. D. Cook and R. H. Green, "Evaluating Power Plant Efficiency: A Hierarchical Model,” Computers \& Opera- tions Research, Vol. 32, No. 4, 2005, pp. 813-823. doi:10.1016/j.cor.2003.08.019

[15] L. Castelli, R. Pesenti and W. Ukovich, "DEA-Like Models for the Efficiency Evaluation of Hierarchically Structured Units," European Journal of Operational Research, Vol. 154, No. 2, 2004, pp. 465-476. doi:10.1016/S0377-2217(03)00182-6

[16] W. D. Cook, D. Chai, J. Doyle and R. Green, "Hierarchies and Groups in DEA," Journal of Productivity Analysis, Vol. 10, No. 2, 1998, pp. 177-198. doi:10.1023/A:1018625424184

[17] T. R. Sexton, R. H. Silkman and A. J. Hogan, "Data Envelopment Analysis: Critique and Extensions,” In: R. H. Silkman, Ed., Measuring Efficiency: An Assessment of Data Envelopment Analysis, Jossey-Bass, San Francisco, 1986.

[18] J. Doyle and R. Green, "Efficiency and Cross-Efficiency in DEA: Derivations, Meanings and Uses," Journal of Operational Research and Society, Vol. 45, No. 5, 1994, pp. 567-578.

[19] A. Charnes and W. W. Cooper, "Programming with Linear Fractional Functional," Naval Research Logistics Quarterly, Vol. 9, No. 3-4, 1962, pp. 181-185. doi:10.1002/nav.3800090303

[20] R. D. Banker, A. Charnes and W. W. Cooper, "Some Models for Estimating Technical and Scale Efficiencies in Data Envelopment Analysis," Management Science, Vol. 30, No. 9, 1984, pp. 1078-1092. doi:10.1287/mnsc.30.9.1078

[21] G. Yu, Q. Wei and P. Brockett, “A Generalized Data Envelopment Analysis Model: A Unification and Extension of Existing Methods for Efficiency Analysis of Decision Making Units,” Annals of Operations Research, Vol. 66, 1996, pp. 47-89.

[22] Y.-M. Wang and K.-S. Chin, "Some Alternative Models for DEA Cross-Efficiency Evaluation,” International Journal of Production Economics, Vol. 128, No. 1, 2010, pp. 332-338. doi:10.1016/j.ijpe.2010.07.032 
M. DIA ET AL.

Appendix A: Data and Results (Efficiency Ratio and Index of Competitiveness)

Table 1. Sectors.

\begin{tabular}{ccccccc}
\hline Sector ID & in1 & in2 & out1 & out2 & E.R. & IC \\
\hline S1 & 23 & 24 & 25 & 26 & 0.97 & 0.578 \\
S2 & 21 & 23 & 24 & 20 & 0.85 & 0.2016 \\
S3 & 26 & 21 & 25 & 28 & 1 & 0.9627 \\
S4 & 21 & 20 & 29 & 22 & 1 & 1 \\
S5 & 21 & 26 & 27 & 26 & 1 & 0.8172 \\
S6 & 22 & 23 & 24 & 20 & 0.817 & 0 \\
\hline
\end{tabular}

Table 2. Companies from sector 1 (S1).

\begin{tabular}{cccccccc}
\hline Company ID & in1 & in2 & in3 & out1 & out2 & E.R. & IC \\
\hline E1 & 10 & 0.8 & 540 & 0.9 & 70 & 0.847 & 0.4602 \\
E2 & 15 & 1 & 480 & 1 & 95 & 0.972 & 0.5702 \\
E3 & 12 & 2.1 & 510 & 0.8 & 75 & 0.734 & 0.1456 \\
E4 & 10 & 0.6 & 420 & 0.9 & 90 & 1 & 0.8289 \\
E5 & 18 & 0.5 & 600 & 0.7 & 80 & 0.829 & 0.3899 \\
E6 & 7 & 0.9 & 520 & 1 & 50 & 1 & 0.6241 \\
E7 & 10 & 0.3 & 500 & 0.8 & 70 & 1 & 1 \\
E8 & 12 & 1.5 & 550 & 0.75 & 75 & 0.66 & 0.0877 \\
E9 & 14 & 0.8 & 570 & 0.65 & 55 & 0.536 & 0 \\
E10 & 8 & 0.9 & 450 & 0.85 & 90 & 1 & 0.6867 \\
\hline
\end{tabular}

Table 3. Companies from sector 2 (S2).

\begin{tabular}{cccccccc}
\hline Company ID & in1 & in2 & in3 & out1 & out2 & E.R. & IC \\
\hline E1 & 35 & 2.8 & 1890 & 3.15 & 245 & 0.681 & 0.33 \\
E2 & 52.5 & 3.5 & 1680 & 3.5 & 332.5 & 0.833 & 0.5522 \\
E3 & 42 & 7.35 & 1785 & 2.8 & 262.5 & 0.627 & 0.2553 \\
E4 & 35 & 2.1 & 1470 & 3.15 & 315 & 0.9 & 0.6794 \\
E5 & 63 & 1.75 & 2100 & 2.45 & 280 & 0.56 & 0.1655 \\
E6 & 24.5 & 3.15 & 1820 & 3.5 & 175 & 0.906 & 0.5429 \\
E7 & 35 & 1.05 & 1750 & 2.8 & 245 & 0.8 & 0.6347 \\
E8 & 42 & 1.75 & 1925 & 2.625 & 262.5 & 0.573 & 0.2251 \\
E9 & 49 & 6.3 & 1995 & 2.275 & 192.5 & 0.456 & 0 \\
E10 & 28 & 3.15 & 1575 & 2.975 & 315 & 0.84 & 0.5791 \\
E11 & 21 & 1.05 & 1575 & 3.325 & 350 & 1 & 1 \\
E12 & 24.5 & 1.05 & 1470 & 3.5 & 350 & 1 & 0.9436 \\
E13 & 28 & 1.05 & 1400 & 3.5 & 332.5 & 1 & 0.893 \\
\hline
\end{tabular}


Table 4. Companies from sector 3 (S3).

\begin{tabular}{ccccccccc}
\hline Company ID & in1 & in2 & out1 & out2 & out3 & out4 & E.R. & IC \\
\hline E1 & 1204.65 & 4.54 & 1707 & 330 & 0.14 & 0.59 & 1 & 1 \\
E2 & 349.53 & 4.97 & 776 & 107 & 0.17 & 0.72 & 0.99 & 0.4322 \\
E3 & 504.88 & 2.98 & 860 & 115 & 0.15 & 0.66 & 1 & 0.5388 \\
E4 & 179.62 & 3.44 & 492 & 52 & 0.17 & 0.72 & 1 & 0.5108 \\
E5 & 196.75 & 3.66 & 265 & 50 & 0.17 & 0.59 & 0.813 & 0.0091 \\
E6 & 457.72 & 4.73 & 881 & 105 & 0.15 & 0.68 & 0.94 & 0.2885 \\
E7 & 338.63 & 5.28 & 722 & 91 & 0.15 & 0.54 & 0.888 & 0.2171 \\
E8 & 207.75 & 1.8 & 337 & 51 & 0.14 & 0.7 & 1 & 0.7108 \\
E9 & 71.72 & 3.16 & 227 & 11 & 0.2 & 0.74 & 1 & 0.6015 \\
E10 & 82.84 & 5.94 & 225 & 10 & 0.2 & 1.02 & 1 & 0.1894 \\
E11 & 56.18 & 7.35 & 33 & 2 & 0.14 & 0.77 & 1 & 0.4331 \\
E12 & 467.69 & 2.56 & 724 & 156 & 0.13 & 0.68 & 1 & 0.9149 \\
E13 & 209.13 & 2.7 & 364 & 70 & 0.17 & 0.7 & 1 & 0.5214 \\
E14 & 105.86 & 1.72 & 190 & 11 & 0.15 & 0.63 & 1 & 0.5944 \\
E15 & 129.41 & 4.55 & 293 & 17 & 0.17 & 0.72 & 0.752 & 0 \\
\hline
\end{tabular}

Table 5. Companies from sector 4 (S4).

\begin{tabular}{|c|c|c|c|c|c|c|c|c|c|}
\hline Company ID & in1 & in2 & in3 & in4 & out1 & out2 & out3 & E.R. & IC \\
\hline E1 & 67.55 & 82.83 & 44.37 & 60.85 & 26.04 & 85 & 23.95 & 0.773 & 0.1562 \\
\hline E2 & 85.78 & 123.98 & 55.13 & 108.46 & 43.51 & 173.93 & 6.45 & 1 & 0.4374 \\
\hline E3 & 80.33 & 104.65 & 53.3 & 79.06 & 27.28 & 132.49 & 42.67 & 0.94 & 0.352 \\
\hline E4 & 205.92 & 183.49 & 144.16 & 59.66 & 14.09 & 196.29 & 16.15 & 0.934 & 0.2565 \\
\hline E5 & 51.28 & 117.51 & 32.07 & 84.5 & 46.2 & 144.99 & 0 & 1 & 0.6452 \\
\hline E6 & 82.09 & 104.94 & 46.51 & 127.28 & 44.87 & 108.53 & 0 & 0.828 & 0.208 \\
\hline E7 & 123.02 & 82.44 & 87.35 & 98.8 & 43.33 & 125.84 & 404.69 & 1 & 0.3809 \\
\hline E8 & 71.77 & 88.16 & 69.19 & 123.14 & 44.83 & 74.54 & 6.14 & 0.686 & 0.1479 \\
\hline E9 & 61.95 & 99.77 & 33 & 86.37 & 45.43 & 79.6 & 1252.62 & 1 & 0.5535 \\
\hline E10 & 25.83 & 105.8 & 9.51 & 227.2 & 19.4 & 120.09 & 0 & 1 & 0.7835 \\
\hline E11 & 27.87 & 107.6 & 14 & 146.43 & 25.47 & 131.79 & 0 & 1 & 0.6563 \\
\hline E12 & 72.6 & 132.73 & 44.67 & 173.48 & 5.55 & 135.65 & 24.13 & 0.763 & 0.0793 \\
\hline E13 & 84.83 & 104.28 & 159.12 & 171.11 & 11.53 & 110.22 & 49.09 & 0.743 & 0 \\
\hline E14 & 202.21 & 187.74 & 149.39 & 93.65 & 44.97 & 184.77 & 0 & 0.799 & 0.1453 \\
\hline E15 & 66.65 & 104.18 & 257.09 & 13.65 & 139.74 & 115.96 & 0 & 1 & 0.9277 \\
\hline E16 & 51.62 & 11.23 & 49.22 & 33.52 & 40.49 & 14.89 & 3166.71 & 1 & 0.9471 \\
\hline E17 & 36.05 & 193.32 & 59.52 & 8.23 & 46.88 & 190.77 & 822.92 & 1 & 1 \\
\hline
\end{tabular}


Table 6. Companies from sector 5 (S5).

\begin{tabular}{cccccccccc}
\hline Company ID & in1 & in2 & in3 & out1 & out2 & out3 & out4 & E.R. & IC \\
\hline E1 & 22 & 50 & 40 & 20 & 43 & 75 & 75 & 1 & 0.8145 \\
E2 & 60 & 100 & 100 & 100 & 60 & 25 & 30 & 1 & 0.6508 \\
E3 & 24 & 17 & 29 & 25 & 50 & 50 & 60 & 1 & 1 \\
E4 & 37 & 23 & 40 & 40 & 13 & 25 & 30 & 1 & 0.6437 \\
E5 & 40 & 30 & 60 & 30 & 50 & 50 & 40 & 0.723 & 0.3175 \\
E6 & 80 & 25 & 90 & 55 & 85 & 10 & 20 & 1 & 0.6183 \\
E7 & 70 & 75 & 18 & 30 & 29 & 7 & 50 & 1 & 0.8548 \\
E8 & 50 & 55 & 55 & 11 & 29 & 10 & 40 & 0.287 & 0 \\
E9 & 100 & 80 & 100 & 90 & 100 & 5 & 25 & 0.864 & 0.4509 \\
\hline
\end{tabular}

Table 7. Companies from sector 6 (S6).

\begin{tabular}{|c|c|c|c|c|c|c|c|c|c|c|}
\hline Company ID & in1 & out1 & out2 & out3 & out4 & out5 & out6 & out7 & E.R. & IC \\
\hline E1 & 48 & 58 & 31 & 51 & 26 & 43 & 18 & 13 & 1 & 0.6447 \\
\hline E2 & 48 & 62 & 67 & 43 & 23 & 26 & 23 & 8 & 1 & 0.6355 \\
\hline E3 & 78 & 100 & 77 & 100 & 100 & 57 & 23 & 100 & 1 & 0.9347 \\
\hline E4 & 68 & 75 & 63 & 70 & 42 & 40 & 19 & 8 & 0.859 & 0.5216 \\
\hline E5 & 44 & 47 & 62 & 49 & 35 & 25 & 23 & 16 & 0.904 & 0.6274 \\
\hline E6 & 52 & 60 & 100 & 68 & 34 & 28 & 75 & 24 & 1 & 1 \\
\hline E7 & 52 & 59 & 72 & 52 & 21 & 20 & 34 & 13 & 0.913 & 0.5774 \\
\hline E8 & 52 & 51 & 51 & 44 & 33 & 23 & 48 & 16 & 0.823 & 0.4805 \\
\hline E9 & 72 & 63 & 38 & 67 & 21 & 18 & 100 & 11 & 0.963 & 0.7407 \\
\hline E10 & 84 & 86 & 88 & 53 & 53 & 100 & 42 & 0 & 1 & 0.8809 \\
\hline E11 & 100 & 73 & 78 & 89 & 88 & 56 & 42 & 16 & 0.783 & 0.3973 \\
\hline E12 & 42 & 26 & 53 & 51 & 21 & 19 & 52 & 2 & 0.929 & 0.6451 \\
\hline E13 & 56 & 23 & 33 & 37 & 18 & 26 & 26 & 11 & 0.591 & 0.1047 \\
\hline E14 & 92 & 99 & 62 & 74 & 57 & 98 & 45 & 5 & 1 & 0.6469 \\
\hline E15 & 56 & 34 & 37 & 30 & 24 & 50 & 47 & 0 & 0.959 & 0.5899 \\
\hline E16 & 46 & 18 & 24 & 25 & 10 & 21 & 8 & 0 & 0.514 & 0 \\
\hline E17 & 72 & 54 & 87 & 43 & 29 & 73 & 38 & 13 & 0.989 & 0.6778 \\
\hline
\end{tabular}


Appendix B: Summary of the Rankings

Table 1. Summary of the rankings of the companies in their sectors.

\begin{tabular}{|c|c|c|c|c|c|c|}
\hline \multirow{2}{*}{ Ranks } & 1 & 2 & 3 & 4 & 5 & 6 \\
\hline & $\mathrm{S} 4$ & S3 & S5 & S1 & S2 & S6 \\
\hline 1 & E17 & E1 & E3 & E7 & E11 & E6 \\
\hline 2 & E16 & E12 & E7 & E4 & E12 & E3 \\
\hline 3 & E15 & E8 & E1 & E10 & E13 & E10 \\
\hline 4 & E10 & E9 & E2 & E6 & E4 & E9 \\
\hline 5 & E11 & E14 & E4 & E2 & E7 & E17 \\
\hline 6 & E5 & E3 & E6 & E1 & E10 & E14 \\
\hline 7 & E9 & E13 & E9 & E5 & E2 & E12 \\
\hline 8 & E2 & E4 & E5 & E3 & E6 & E1 \\
\hline 9 & E7 & E11 & E8 & E8 & E1 & E2 \\
\hline 10 & E3 & E2 & & E9 & E3 & E5 \\
\hline 11 & E4 & E6 & & & E8 & E15 \\
\hline 12 & E6 & E7 & & & E5 & E7 \\
\hline 13 & E1 & E10 & & & E9 & E4 \\
\hline 14 & E8 & E5 & & & & E8 \\
\hline 15 & E14 & E15 & & & & E11 \\
\hline 16 & E12 & & & & & E13 \\
\hline 17 & E13 & & & & & E16 \\
\hline
\end{tabular}


Table 2. Ranking of the companies in the economy.

\begin{tabular}{|c|c|c|c|c|c|c|c|c|}
\hline IOC & Company ID & Rank & IOC & Company ID & Rank & IOC & Company ID & Rank \\
\hline 1 & E17S4 & 1 & 0.676 & E3S4 & 28 & 0.41815 & E7S2 & 55 \\
\hline 0.98135 & E1S3 & 2 & 0.63405 & E9S5 & 29 & 0.4086 & E8S5 & 56 \\
\hline 0.97355 & E16S4 & 3 & 0.63235 & E10S1 & 30 & 0.39035 & E10S2 & 57 \\
\hline 0.96385 & E15S4 & 4 & 0.62825 & E4S4 & 31 & 0.3769 & E2S2 & 58 \\
\hline 0.9388 & E12S3 & 5 & 0.6256 & E6S3 & 32 & 0.37225 & E6S2 & 59 \\
\hline 0.9086 & E3S5 & 6 & 0.604 & E6S4 & 33 & 0.37035 & E9S6 & 60 \\
\hline 0.89175 & E10S4 & 7 & 0.60105 & E6S1 & 34 & 0.3618 & E3S1 & 61 \\
\hline 0.83675 & E8S3 & 8 & 0.6008 & E11S2 & 35 & 0.3389 & E17S6 & 62 \\
\hline 0.836 & E7S5 & 9 & 0.5899 & E7S3 & 36 & 0.33285 & E8S1 & 63 \\
\hline 0.82815 & E11S4 & 10 & 0.5781 & E1S4 & 37 & 0.32345 & E14S6 & 64 \\
\hline 0.8226 & E5S4 & 11 & 0.57605 & E10S3 & 38 & 0.32255 & E12S6 & 65 \\
\hline 0.81585 & E1S5 & 12 & 0.5741 & E2S1 & 39 & 0.32235 & E1S6 & 66 \\
\hline 0.789 & E7S1 & 13 & 0.57395 & E8S4 & 40 & 0.31775 & E2S6 & 67 \\
\hline 0.7821 & E9S3 & 14 & 0.57265 & E14S4 & 41 & 0.3137 & E5S6 & 68 \\
\hline 0.77855 & E14S3 & 15 & 0.5726 & E12S2 & 42 & 0.29495 & E15S6 & 69 \\
\hline 0.77675 & E9S4 & 16 & 0.56735 & E5S5 & 43 & 0.289 & E9S1 & 70 \\
\hline 0.75075 & E3S3 & 17 & 0.5473 & E13S2 & 44 & 0.2887 & E7S6 & 71 \\
\hline 0.74205 & E13S3 & 18 & 0.53965 & E12S4 & 45 & 0.2658 & E1S2 & 72 \\
\hline 0.73675 & E4S3 & 19 & 0.5191 & E1S1 & 46 & 0.2608 & E4S6 & 73 \\
\hline 0.734 & E2S5 & 20 & 0.5 & E13S4 & 47 & 0.24025 & E8S6 & 74 \\
\hline 0.73045 & E4S5 & 21 & 0.5 & E6S6 & 48 & 0.22845 & E3S2 & 75 \\
\hline 0.7187 & E2S4 & 22 & 0.4859 & E5S3 & 49 & 0.21335 & E8S2 & 76 \\
\hline 0.71775 & E6S5 & 23 & 0.48395 & E5S1 & 50 & 0.19865 & E11S6 & 77 \\
\hline 0.70345 & E4S1 & 24 & 0.48135 & E15S3 & 51 & 0.18355 & E5S2 & 78 \\
\hline 0.6979 & E11S3 & 25 & 0.46735 & E3S6 & 52 & 0.1008 & E9S2 & 79 \\
\hline 0.69745 & E2S3 & 26 & 0.4405 & E4S2 & 53 & 0.05235 & E13S6 & 80 \\
\hline 0.69045 & E7S4 & 27 & 0.44045 & E10S6 & 54 & 0 & E16S6 & 81 \\
\hline
\end{tabular}




\section{Appendix C: Improvement Opportunities}

Table 1. Improvement opportunities for the sectors in the economy.

\begin{tabular}{ccccc}
\hline Sector ID & in1 & in2 & out1 & out2 \\
\hline S1 & -0.6866 & -0.7164 & 0.4179 & 0 \\
S2 & -3.15 & -4.05 & 0 & 0 \\
S6 & -4.0369 & -4.2204 & 0 & 0 \\
\hline
\end{tabular}

Table 2. Improvement opportunities for the companies in their sector 1.

\begin{tabular}{cccccc}
\hline Company ID & in1 & in2 & in3 & out1 & out2 \\
\hline E1 & -1.5337 & -0.1227 & -92.0246 & 0 & 0 \\
E2 & -3.8889 & -0.3333 & -13.3333 & 0 & 5 \\
E3 & -3.1912 & -1.5621 & -135.6273 & 0 & 4.0256 \\
E5 & -7.5238 & -0.0857 & -102.8571 & 0.1714 & 0 \\
E8 & -4.0791 & -0.9207 & -186.9596 & 0 & 0 \\
E9 & -6.7572 & -0.371 & -264.3243 & 0 & 9.8151 \\
\hline
\end{tabular}

